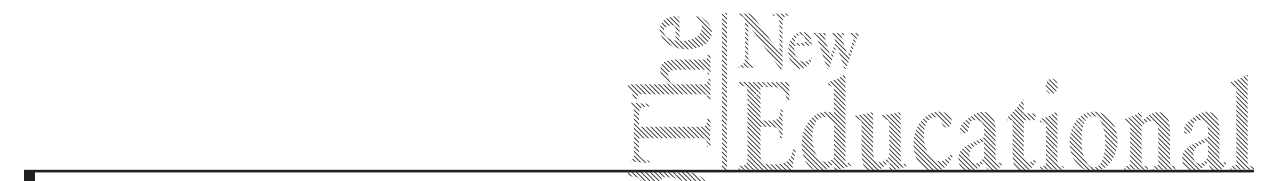

Alexander O. Prokhorov, Mark G. Yusupov

Russia.

Viktor V. Plokhikh

Ukraine.

\title{
Cognitive States \\ in the Process of Students' Intellectual Activity
}

DOI: 10.15804/tner.2015.41.3.21

\begin{abstract}
Cognitive states are typical of students' educational activity, which is accompanied by high activity of cognitive processes. Management of this activity is impossible without the knowledge of the structure, function, and mechanisms of actualization of cognitive states in various learning situations. The research relevance of the problem of cognitive states in the context of students' intellectual activity is due to their unique role in the regulation of the thinking process, maintaining a steady focus on the solution of the problem within a certain period of time. The purpose of this article is to study the structure of the cognitive states that arises in the process of solving intellectual problems (through the example of carrying out R. Amthauer's intelligence structure test). Leading methods to the study of this problem were tests with standardized questionnaires and retrospective self-reports. According to the results of factor analysis, ten key factors underlying the structure of the typical cognitive state of interest/mental stress have been identified. A system-forming factor of this condition has been emphasized, which is an "attitude" to intellectual activity in the context of the overall semantic orientation of the subject. The obtained results can be of interest to researchers in the field of psychology of emotions as well as to specialists involved in the diagnosis of students' intellectual abilities.
\end{abstract}

Keywords: intellectual activity, cognitive states, interest, structure 


\section{Introduction}

Cognitive states are one of the types of mental states of the individual, integrating mental processes and properties that are necessary for the effective performance of cognitive tasks arising in the course of human life. Cognitive states accompany the learning process and are experienced as thoughtfulness, curiosity, surprise, doubt, concentration, etc. These states are closely connected with intellectual activity, are caused by the need for orientation (e.g., interest) or the arising mental distress in the course of activity (e.g., mental stress) (Izard, 1991).

The basis for selection of a class of cognitive states, in addition to the dominance of the cognitive component, can also be the inclusion of certain procedural and sustainable human qualities in the structure of the state. The selected and described "integrative function" of mental states can serve as the theoretical basis of these ideas (Prokhorov, 1994). These views are also confirmed by the studies of the condition of interest (Prokhorov et al., 2015), chronic fatigue (Marcora et al., 2009), the state of flow (Csikszentmihalyi \& Nakamura, 2011), etc. Another example is the studied daily trance state (Prokhorov \& Yusupov, 2012). The core of the manifestations of this state is the subject's cognitive processes. Among the central features of the daily trance there are: the novelty in the perception of reality, the activity of imagination, thoughts of philosophical nature in the background of the activity of everyday thinking reduction, memory activity and the availability of personal experience, a high level of focus on inner feelings and sensations, as well as value characteristics (the values of knowledge, development and productive life).

Review of the current literature shows that the place and role of cognitive states in the process of professional training of future specialists is not taken into account, so the studies on cognitive states of "student age" are relevant, because it is this age period that is characterized by high potential for personal and professional development.

\section{Materials and Methods}

\section{The purpose and the research issue}

Due to the fact that the cognitive states are holistic psychic phenomena, it is necessary to reveal their structural (systemic) organization. The solution to this issue is the purpose of this article. 


\section{Participants}

First year students at Kazan Federal University took part in the research; their average age was 18.6 years. The sampling consisted of 146 people.

\section{Procedures and instruments}

During the academic semester the following characteristics were measured: metacognitive involvement in the activity (MAI) (Schraw \& Dennison, 1994), the level of reflexivity (Grant, 2001), the characteristics of temperament (EPI) (H. Eysenck \& S. Eysenck, 1975), learning (Anastasi \& Urbina, 1997), the level of verbal creativity (S. Mednick \& M. Mednick, 1967), the ability to self-manage (Gabdreeva \& Yusupov, 2013), communication styles (Leary, 1957), the level of subjective control (Rotter, 1966), the level of emotional intelligence (Goleman, 1995), purpose-in-life orientations (Leontyev, 2006), and personality traits (Cattell \& Mead, 2008).

At the final stage of the research, to measure the level of intelligence and enhance the learning states of students an intellectual test was conducted (Amthauer, 1970). Immediately after executing it the students were asked to evaluate the characteristics of the cognitive states according to a special questionnaire consisting of 40 indicators related to different components of the mental state (physiological processes, emotions, mental processes, and behavioral characteristics).

\section{Data analysis}

The results of the empirical study were processes using the procedure of factor analysis (SPSS 19.0 program). The principal component method was used, oblique Promax rotation, which allows for calculating correlations between factors.

\section{Results}

\section{Phenomenological analysis of the students' cognitive states}

Analysis of the testees' self-reports showed that the states arising in the course of performing intellectual tasks are quite complex. Thus, the students noted the intense emotions of indignation, excitement, anxiety, resentment, sadness, vivacity, fun, and anger. The most frequently described were the feelings of excitement (16\% of the testees), boredom (11\%) and cognitive activity (9\%).

In addition, intellectual activity was combined with the functional conditions such as fatigue, apathy, indifference, drowsiness, and mental stress. Among the states, the students most frequently mentioned the cognitive state of interest (48\%). 
The most typical combination (more than $55 \%$ of the respondents) is formed by the combination of "interest - mental stress"; in phenomenological descriptions the central position is given to the experiences of interest.

Thus, while performing the test of intelligence, the typical experience was a combination of interest and mental effort. Further statistical analysis was carried out for the data of only those respondents whose experiences like that were dominant (86 people).

\section{Factor structure of the interest/mental stress state}

A correlation matrix including 79 variables was factored by the principal component method. 17 factors were extracted with eigenvalues greater than unity. The first 10 factors explain $81.3 \%$ of the aggregate (total) variance of the variables.

The first factor included the following variables: the overall meaningfulness of life indicator (0.980); meaningfulness of life process (0.927); meaningful goals in life (0.926); learning (0.802); meaningfulness of life effectiveness (0.786); internal locus of control (0.709); and goal-setting ability (0.672).

In general, the first factor shows dependence of the intellectual activity and the conditions accompanying it on the subjective significance of the tasks being solved in the context of the overall semantic orientation of the subject. In addition, the actualization and experience of the cognitive states depend on the ability to learn and the process of goal setting - mental activity, forming a subjective model of the desired result.

Thus, the first factor can be called a factor of "attitude" of the subject of intellectual activity to the tasks at hand and the process of cognition in general. Due to the action of this factor a semantic regulation of the educational-cognitive activity is provided.

The second factor included the following indicators: adequacy of behavior (0.885), reasonableness of conduct (0.884); the sequence (purpose) of behavior (0.763); awareness of perception (0.749); improvement of the coordination of movements (0.725); ability to predict (0.633); and metacognitive involvement in activities (0.613).

The second factor includes characteristics of goal-oriented behavior, ability to predict and metacognitive regulation of intellectual activity ability. Based on the psychological content of these indicators, the second factor can be identified as "engagement in intellectual activity".

The third factor is made up of the following variables: authoritarianism (0.907); selfishness (0.733); domination (0.700); independence (0.646); and verbal creativity $(-0.521)$. 
The third factor can be called a factor of "social regulation of cognitive activity". Organization of variables shows that intensification and the course of cognitive states are associated with the dominant and independent type of attitude to others. In the structural-functional organization of cognitive states, this factor is opposite to the "verbal creativity" ability.

The fourth factor includes the following indicators: management of emotions (0.901); self-motivation (0.736); hyperpnoe (0.715); straightness $(-0.664)$; neuroticism $(-0.654)$; anxiety $(-0.647)$; and barriers to thinking $(-0.625)$.

The fourth factor clearly relates to emotional stability, so next we entitle it "the self-regulation of emotions" in the process of intellectual activity of the subject.

The fifth factor included the variables: emotional stability (0.868); the ability to plan (0.823); the general self-management ability (0.688); closeness (0.674); vigor (0.636); the ability to take action (0.624); the ability to analyze contradictions (0.571); high self-esteem (0.542); and reflexivity (0.469).

The fifth factor can be called "the self-management ability" as its core consists of 4 indicators on the self-management test. This leading position is taken by the planning process, aimed at creating a subjective model of the means of achieving the objectives and the sequence of their application.

The sixth factor consists of the following indicators: gaiety (0.839); fervor (0.731); optimism (0.726); advanced thinking (0.722); uncontrollability $(-0.597)$; dependence on group $(-0.588)$; and a sense of amplifying cardiac activity (0.557).

The sixth factor shapes the experience performance indicators. Interestingly, this factor integrates extremely positive emotions (happiness, fervor, optimism), which once again demonstrates the positivity condition of interest. This factor can be called the "experiences activity" factor.

The seventh factor included the following variables: extraversion (0.791); the ability to correct an activity (0.761); and boldness ( 0.721$)$.

The content of the seventh factor shows that cognitive states are associated with the properties of temperament, the function of volitional control of behavior (boldness), and the ability to adjust the activity, thinking and emotions. It is not easy to interpret this factor, however, according to the meaning of its constituent variables, let us call it a "personality" factor.

The eighth factor included the following variables: trust (0.775); friendly style of attitude to others (to 0.671 ); empathy (0.637); friendliness (0.590); and recognition of emotions of others (0.557).

The eighth factor is characterized by a trusting and friendly attitude towards others, so it is logical to headline it as a factor of "a friendly attitude to others". 
The ninth factor included the following variables: total score on Amthauer's intelligence test (0.754); and the ability to assess the quality of activity (0.680).

The ninth factor combines variables related to the cognitive component of the cognitive states; therefore, it can be defined as the factor of "general intelligence". The role of this factor in the general factor structure helps to assert that the level of general intelligence development is not fundamental to students' structure of cognitive mental states.

The tenth factor is associated with the following indicators: radicalism (0.864); hardness (0.796); numerical series (0.631); and spatial imagination (0.611).

The tenth factor combined intellectual and personality characteristics. This factor can be interpreted as the factor of "personal regulation of cognitive abilities".

The eleventh factor included the following variables: ease of remembering (0.827); and the logic of thought (0.703).

The eleventh factor forms two indicators of the intensity of cognitive processes (memory and thinking). Therefore it can be considered the "activity of cognitive processes" factor.

The twelfth factor integrates the following variables: altruism (0.790); carelessness (0.671); and the obeying style of attitude to others (0.649).

The twelfth factor presents a "dependent behavior style", because it groups the indicators showing the predominance of conforming attitudes, congruence in contacts with others, self-doubt, compliance with the opinion of others and the tendency to compromise.

The thirteenth factor consists of the following indicators: usability (0.856); and emotional awareness (0.610).

The thirteenth factor can be labeled as "practicality".

The fourteenth factor included the following variables: increased physical activity (0.742); briskness of experiences (0.669); and conscientiousness (0.602).

The fourteenth factor primarily combines the characteristics of experiences and physical activity. This factor can be labeled as "mental state activity".

The fifteenth factor includes the following indicators: radicalism (0.764); and ability to self-control (0.727).

Radicalism as a personality trait is characterized also by the presence of intellectual interests, as well as developed analytical thinking, a focus on analytical and theoretical activity. Thus, the fifteenth factor has to do with personal regulation of intellectual activity. However, it is reasonable to call it "radicalism". 
The sixteenth factor included the following variables: aggressive style of attitude to others (0.706); insufficient self-control (0.686); suspicion (0.674); extraversion (0.609); and clarity of ideas (0.519).

The sixteenth factor is characterized by an aggressive attitude towards others and poor self-control. This factor can be interpreted as "external locus of control".

The seventeenth factor consists of the following indicators: ability to generalize concepts (0.722); and internal tensions (0.621).

The seventeenth factor can be called the "verbal-logical thinking activity" factor.

Thus, according to the results of statistical processing, 10 basic factors were selected (which explain $81.3 \%$ of the total variance of the original variables) that define the structure of the cognitive states:

1. "Attitude to intellectual activities" (18.3\% of the explained variance),

2. "Engagement in intellectual activity" (11.5\%),

3. "Social regulation of cognitive activity" (9.9\%),

4. "Self-regulation of emotions" (8.9\%),

5. "Self-management ability" (6.9\%),

6. "Activity of experiences" (6.1\%),

7. The factor of "personality" (5.9\%),

8. "Friendly attitude towards others" (5.1\%),

9. "General intelligence" (4.8\%),

10. The factor of "personal regulation of cognitive abilities" (3.9\%).

\section{Interdependence of the factors determining the structure of the interest/mental stress state}

Let us consider the most stable relationship between the selected factors (cf., Table 1).

At the level of statistical significance $p \leq 0.001$ there are a total of 6 relations. The most powerful of them is the correlation of the factors of "social regulation of cognitive activity" and "activity of cognitive processes" (0.521). The factor of "personality" has the greatest number of strong relations with the factors of "selfregulation of emotions", "self-management ability", and "activity of mental states". Thus, individual personality characteristics play a significant role in the structural and functional organization of the cognitive states.

The most dependent factors in the structure of the cognitive states are: factor 4 "self-regulation of emotions," factor 7 "individuality" and factor 14 "the activity of the mental state". 


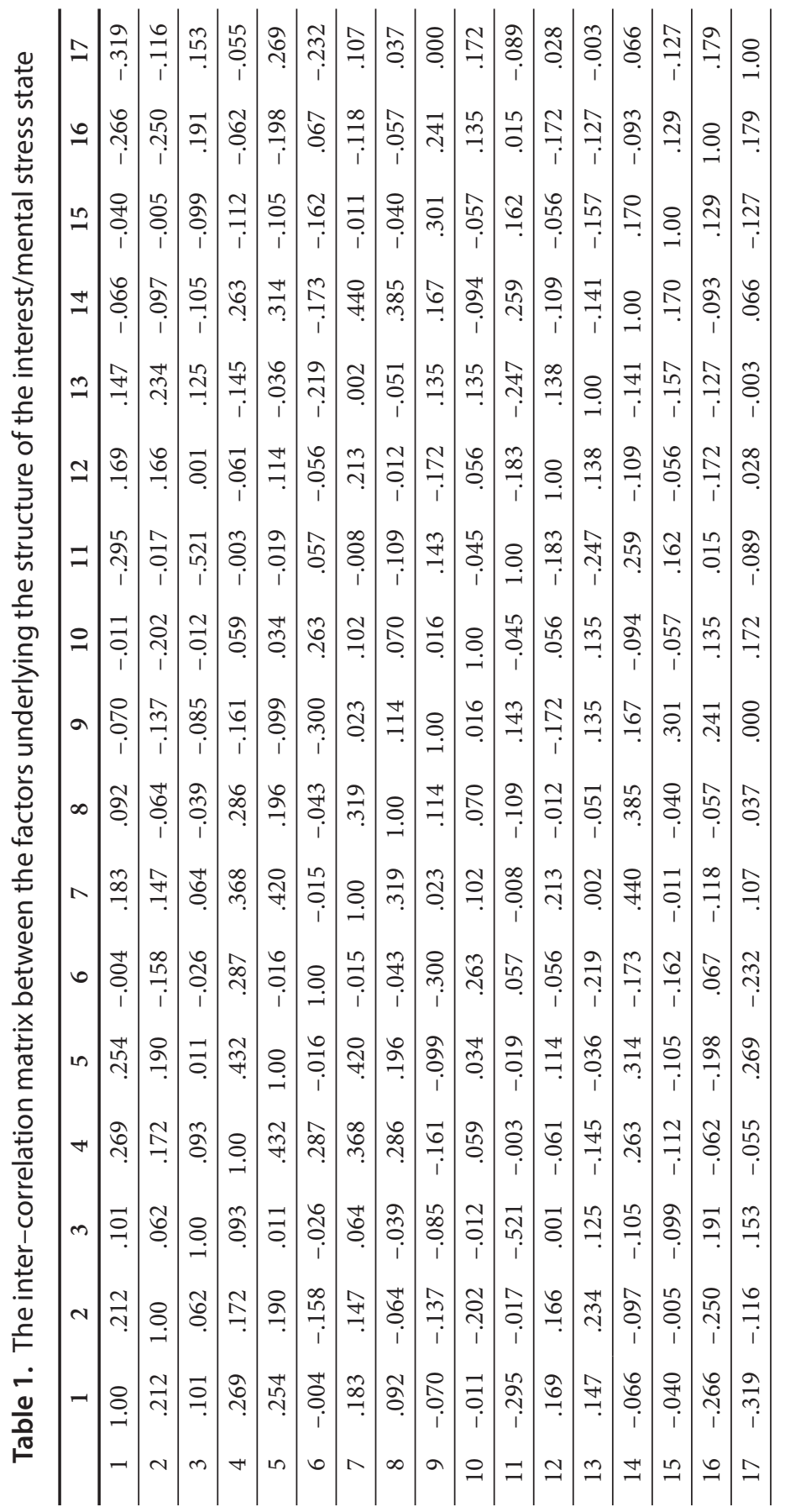




\section{Discussions}

First of all, the limitations of the conducted research should be noted. The characteristics of the interest/mental stress state were obtained by the method of retrospective self-evaluation. Methods of self-analysis are quite scientific and reveal aspects of human cognition inaccessible to other methods (Ericsson \& Simon, 1980). However, it is obvious that the accuracy of the information thus obtained depends on the reflective abilities and short-term memory capacity of the subject.

In previous research we studied the state of interest in real learning activities. It was found that in the organization of the state of interest the leading role is played by the factor of metacognitive regulation of learning and cognitive activity (Prokhorov et al., 2015). In the situation of executing intellectual tests, the factor of semantic regulation of intellectual activity comes to the fore. This means that the cognitive states accompanying the intellectual activity are largely dependent on the subjective importance of the tasks being solved and the students' attitudes to the situation of intelligence diagnostics in general. Previously, the influence of personal meaning on the structure of the cognitive states was shown by us through the example of two kinds of relationships - the procedural personal meaning, associated with the implementation of activities and the personal meaning of self-assertion, aimed at preserving a positive image of one's " $\mathrm{I}$ ". The procedural personal meaning contributes to the decrease in the intensity of the experienced emotions and the increasing productivity of the cognitive processes, thereby contributing to optimum organization of the cognitive states (Prokhorov \& Yusupov, 2015).

In this research, the combination of the state of interest and mental stress is indirect evidence that the purpose of the respondents was exactly the solution of the proposed problems, and not testing of the limits of their intellectual abilities, which carries a potential threat to students' self-esteem. This is evidenced also by the fact that the majority of the tested subjects evaluated the state of interest/mental stress as positive. Thus, the obtained results should be classified as "operational interest", characterized by the coincidence of the motive and the purpose of intellectual activity (to solve the proposed experimental tasks as best as possible).

The presence of four basic factors related to various aspects of self-regulation in the structure of the state of interest seems to be a noteworthy fact. Thus, this fact confirms the results of the earlier experimental studies, which showed the 
regulatory role of the state of interest in relation to the motivational and cognitive resources of the individual (Thoman et al., 2011; Silvia et al., 2009).

\section{Conclusions}

The analysis of the examined subjects' self-reports indicates that it is quite difficult to identify cognitive states in "pure" form. In the presented descriptions the cognitive states were the result of the interaction of emotions (e.g., excitement), learning states (e.g., attention activity), being relevant to the functioning level of the intellectual abilities, as well as social feelings (e.g., feelings of duty, responsibility, etc.). The most typical cognitive state of the students in the course of executing the intellectual tests is the state of interest combined with mental stress (more than $55 \%$ of the respondents).

According to the results of statistical processing of the data, 10 key factors were highlighted (which explain $81.3 \%$ of the total variance of the variables), underlying the interest/mental stress state structure. The core factor of this condition is the factor of "attitude towards intellectual activity" in the context of the overall semantic orientation of the subject. This factor has an inverse correlation $(\mathrm{p} \leq 0.01)$ with the activity factors of the cognitive processes and verbal-logical thinking.

Thus, the interest/mental stress state activated during intellectual activity of students is characterized by multiple manifestations of the psyche (semantic, cognitive, emotional, social and psychological) and a multi-component structure. The level of development of general intelligence and certain cognitive abilities plays a secondary role in the organization of the state of interest/mental stress, which is largely due to students'ability to learn.

\section{Acknowledgments}

1. The research was conducted with the support of the Russian Humanitarian Scientific Fund and the Government of the Republic of Tatarstan, project No. 15-16-16002.

2. This work was funded by the subsidy allocated to Kazan Federal University for the state assignment in the sphere of scientific activities. 


\section{References}

Amthauer, R. (1970). Intelligenz-Struktur-Test. I-S-T 70. Gottingen: Hogrefe.

Anastasi, A. \& Urbina, S. (1997). Psychological Testing (7th ed., p. 721). NJ: Prentice Hall, Upper Saddle River.

Cattell, H.E.P., \& Mead, A.D. (2008). The sixteen personality factor questionnaire (16PF). In G. Boyle, G. Matthews, \& D.H. Saklofske (Eds.), The SAGE handbook of personality theory and assessment (Vol. 2, Personality measurement and testing, pp. 135-178). Los Angeles, CA Sage.

Csikszentmihalyi, M. \& Nakamura, J. (2011). Positive psychology: Where did it come from, where is it going? In K.M. Sheldon, T.B. Kashdan, \& M.F. Steger (Eds.), Designing positive psychology (pp. 2-9). New York, NY: Oxford University Press.

Ericsson, K.A. \& Simon, H.A. (1980). Verbal reports as data. Psychological Review, 87, $215-251$.

Eysenck, H.J. \& Eysenck, S.B.G. (1975). Manual of the Eysenck Personality Questionnaire. London: Hodder and Stoughton.

Gabdreeva, G.S. \& Yusupov, M.G. (2013). Self-regulation of mental states: psychological technologies and diagnostics. Kazan: Otechestvo.

Goleman, D. (1995). Emotional intelligence. New York, NY: Bantam Books, Inc.

Grant, A.M. (2001). Rethinking Psychological Mindedness: Metacognition, Self-reflection, and Insight. Behavior Change, 18(1), 8-17. http://dx.doi.org/10.1375/bech.18.1.8

Izard, C.E. (1991). The Psychology of Emotions (p. 451). New York, NY: Plenum Press. http:// dx.doi.org/10.1007/978-1-4899-0615-1

Leary, T. (1957). Interpersonal Diagnosis of Personality: A functional theory and methodology for personality evaluation. New York, NY: Ronald Press Company.

Leontyev, D.A. (2006). Test of life-meaningful orientations (LMO). Psychodiagnostic series. Moscow, M: Smysl.

Marcora, S.M., Staiano, W. \& Manning, V. (2009). Mental fatigue impairs physical performance in humans. Journal of Applied Physiology, 106(3), 857-864. DOI:10.1152/ japplphysiol.91324.2008.

Mednick, S.A. \& Mednick, M.T. (1967). Examiner's manual: Remote Associates Test. Boston, MA: Houghton Mifflin.

Prokhorov, A.O. \& Yusupov, M.G. (2012). Everyday trance state: Phenomenology and regularities. Psikhologicheskii Zhurnal, 33(1), 88-100. ISSN: 02059592.

Prokhorov, A.O. \& Yusupov, M.G. (2015). Interaction of Mental States and Cognitive Processes in Learning Activity of Students. The Social Sciences, 10, 81-88. DOI: 10.3923/ sscience.2015.81.88.

Prokhorov, A.O. (1994). Mental states and their functions. Kazan: Kazan State Pedagogical University.

Prokhorov, A.O., Chernov, A.V. \& Yusupov, M.G. (2015). Cognitive states in educational activity of students: Structural-functional aspect. Asian Social Science, 11(1), 213-218. DOI: $10.5539 /$ ass.v11n1p213. 
Rotter, J.B. (1966). Generalized expectancies for internal versus external control of reinforcement: Psychological Monographs. General and Applied 80 (1), 1-28.

Schraw, G. \& Dennison, R.S. (1994). Assessing Metacognitive Awareness. Contemporary Educational Psychology, 19, 460-475. DOI: 10.1006/ceps.1994.1033.

Silvia, P.J., Robert, A.H. \& Templin, J.L. (2009). Are the sources of interest the same for everyone? Using multilevel mixture models to explore individual differences in appraisal structures. Cognition and Emotion, 23(7), 1389-1406. DOI: 10.1080/026999309 02850528 .

Thoman, D.B., Smith, J.L. \& Silvia, P.J. (2011). The resource replenishment function of interest. Social Psychological and Personality Science, 2, 592-599. DOI: 10.1177/1948550 6114025. 